\title{
Dissecting home regionalization: how large does the region loom?
}

\author{
André Sammartino and Thomas Osegowitsch \\ Department of Management and Marketing, \\ University of Melbourne
}

Forthcoming in 2013 in Multinational Business Review,

Vol. 21 No. 1, pp. 45-64

\begin{abstract}
Purpose - The paper aims to motivate more rigorous theoretical and empirical specification of the home regionalization phenomenon, in particular the dynamics of shifting advantage over time within a multinational enterprise. It aims to improve dialogue among regionalization researchers.

Design/methodology/approach - Contrasting the economizing and behavioral perspectives on internationalization, the paper presents five different archetypes of the home-regionalization phenomenon. These archetypes are predicated on strategic management stylizations of competitive advantage.

Findings - The paper demonstrates that the notion of home regionalization as a dominant and superior model for firm internationalization remains a promising yet under-explained and inconsistently articulated thesis. By introducing and exploring the archetypes, it shows the diversity of home regionalization theses, and the prospect that multiple forms of regionalization may be at play for different firms, industries and locations.

Originality/value - The paper presents the full complement of archetypes of the home-regionalization phenomenon and explores their corresponding assumptions. These explorations open up new empirical and theoretical research avenues for distinguishing any genuine region effects.

Keywords - Regionalization, Home regionalization, Regional strategy, Home-regional strategy, Globalization, Global strategy, Semi-globalization, Regional development

Paper type - Conceptual paper
\end{abstract}

\section{Introduction}

Over the past decade, a stream of international business (IB) literature has emerged refuting the assumption and assertion of globally competitive multinational enterprises (MNEs). Instead, it is argued that we should focus our attention on the more typical outcome: MNEs whose international operations are confined mostly to the continental neighborhood of their home country, i.e. their home region.

The geographic scope of internationalization strategies and their performance implications is central to IB as a research domain. Before we abandon the large and influential literature on global strategy (Bartlett and Ghoshal, 1989; Doz et al., 2001), we must be sure that the home-region phenomenon is empirically significant, and theoretically distinct over and above the various proximity/distance elements in existing IB theory.

The home region may be no more than a collective noun for neighboring countries or markets. If the home region, and regions in general, parsimoniously capture the myriad country-to-country distances, this does simplify analyses of firm expansion. We argue, however, that for regions to matter in IB theory, regions should be distinct domains in which firm-specific advantages (FSAs) are created or adapted, and regions should be discrete loci for decision-making. 
Central to both economistic and behavioral theorizing on internationalization is the interplay between FSA reach (Vernon, 1979; Rugman, 2005) and location choices. In this paper, we offer five distinct archetypes or iterations of FSA reach, and consider how these correspond with arguments proposed in the regionalization literature. Rather than being beholden to a particular theory, we are interested here in the details of the phenomenon of home regionalization (Cheng, 2007). Our primary concern is with specific patterns of home regionalization behavior, framed as archetypes of FSA reach. These archetypes are valid irrespective of the particular mechanisms espoused by a variety of theories used to frame home regionalization. For each archetype, we discuss the extent to which the regional border represents a meaningful barrier to MNE expansion. These insights allow us to assess the relevance of the homeregionalization phenomenon and to raise more fundamental questions about the merit of the region concept and any region effect.

\section{Research into home regionalization}

Several disparate research streams are interested in regional phenomena. In recent years, there has been a resurgence of interest in the role of geography among the IB community (Buckley and Ghauri, 2004). This has coincided with a re-discovery of the region as a potentially relevant level of analysis - between the long-established levels of the country and the world. Examples include investigations into the role of regional headquarters (Enright, 2005; Piekkari et al., 2010), regional strategy (Morrison et al., 1991; Ghemawat, 2007) and the phenomena of new regionalization and semiglobalization (Ethier, 1998; Ghemawat, 2003).

In this paper, we focus on the particular strand of regionalization research that explores firms' orientations towards their home region. ${ }^{1}$ To set these contributions apart from other regionalization literature, we adopt the term "home regionalization".

The notion of home regionalization gained attention when it was postulated by a number of IB researchers looking at the spread of MNEs (Rugman, 2000, 2005; van Tulder et al., 2001). Based on firm-level sales data (and, less frequently, asset data), they argued that, contrary to opinions promulgated in the business press and many textbooks, the world's largest firms are overwhelmingly active in their home region, with few expanding into host regions. The notion of world-conquering MNEs also sits uncomfortably with research suggesting that, in a good number of industries, global concentration has declined in recent years while regional concentration has risen (Ghemawat, 2005).

Although the home regionalization thesis comes with varying degrees of strength, the central argument is that an MNE's competitiveness is likely to vary across regions. In effect, this research stream is concerned with MNE performance across geographic locales. In the absence of geographically segmented profitability data, the achievement of substantial sales is taken as an indicator of the firm's ability to deploy its FSAs in a given region (and/or to build new FSAs in that region). A firm that achieves host region market shares that are similar to its home-region share is viewed as a "global firm", having successfully translated its FSAs into offerings capable of attracting customers around the world. A firm that achieves balanced market shares across the home region and one particular host region might be considered a "biregional firm" in this research stream (Rugman and Verbeke, 2004). 
Thus, it should be clear that home-regionalization research is chiefly concerned with the performance of market-seeking behavior, i.e. firm internationalization in search of additional customers. Yet, IB researchers recognize market seeking as only one of several motives for firm international expansion (Dunning, 2000). Some scholars identify it as the preeminent motive (Hennart, 2007), but most firms' internationalization is likely to be driven by a combination of motives. Moreover, motives are liable to change over time (Luo and Rui, 2009). The commonly used sales criterion conveniently sidesteps these complications in that it only captures marketseeking behavior and, as such, is unencumbered by instances of mixed-motive internationalization. $^{2}$

The most common region definition in this research stream is triad-based, incorporating various versions of Europe, Asia, and (North) America. There is, however, debate in the literature as to the most appropriate geographic region boundaries. $^{3}$ In our opinion, the more fundamental question is whether the region, irrespective of its dimensions, matters in explaining the sales footprints of MNEs. The different archetypes of FSA reach sketched out below are valid irrespective of the particular region definition employed.

\section{Theories of home regionalization}

Reflecting an IB tradition of interest in a phenomenon rather than a particular theory (Cheng, 2007), much of the work on home regionalization to date has been empirically driven. Early works (Rugman, 2000, 2005; van Tulder et al., 2001) using cross-sectional data sets on the sales distributions of the world's largest MNEs set the scene. Their results show a predominance of home region sales and sparked a raft of empirical papers investigating the extent and dynamics of home regionalization (Arregle et al., 2009; Asmussen, 2009; Filippaios and Rama, 2008; Flores and Aguilera, 2007; Osegowitsch and Sammartino, 2007, 2008; Rugman and Oh, 2010, 2012). These works are in agreement that large firms are oriented towards their home region (in terms of sales as well as assets), although a significant portion of it would seem to be a home-country orientation. There is some disagreement about the evolution of that orientation over time.

The field of IB encompasses two broad classes of theories with distinctive conceptualizations of the firm's decision-making process (Buckley et al., 2007). Both of these paradigms have been used to theorize about home-regionalization outcomes. While there are many commonalities (Rugman and Verbeke, 2004), they do have somewhat differing theoretical foci and emphases.

In the more economistic theories (OLI and internalization/transaction cost theories), firms are portrayed as quasi-rational entities that weigh the costs and benefits of particular investment options. Accordingly, the location decision is a purposeful, though boundedly rational, decision with the explicit objective of longterm profit maximization.

Behavioral theories (such as Uppsala, innovation, and cognitive theories) espouse a more loosely structured decision process. Here too, managers are viewed as risk averse, grappling with even more severely limited information and a more bounded capacity to process information. With an emphasis on significant resource constraints, continuous learning and cognitive framing, behavioral approaches allow for more substantial managerial discretion and judgment. The economistic notion of choosing 
the best alternative (albeit under certain constraints) gives way to notions of satisficing. Satisficing refers to "a course of action [here, the choice of a particular location] that is satisfactory or 'good enough" (Simon, 1979, p. 3).

Both of these two paradigms highlight the interplay between FSAs and location choices. Most importantly, they are united in portraying distance, however defined, ${ }^{4}$ as mostly problematic. ${ }^{5}$ As a result, theories in both camps espouse a tendency for firms to pursue proximate markets in preference to more distant locations. ${ }^{6}$

In the economistic tradition, distance is seen as giving rise to a variety of costs and risks. Rugman and Verbeke's (2005) transaction-cost account is the best-known economistic exponent and the only dedicated theory of home regionalization. The central tenet of their contribution is that most non-location-bound FSAs are in fact home-region-bound, thus hampering the firm's efforts at exploiting these advantages beyond the home region. The difficulty leveraging advantages beyond the home region is sometimes presented in terms of a so-called inter-regional liability of foreignness (LOF), ${ }^{7}$ such that there is a substantial cost differential between home-regional and host-regional expansion.

Most non-location-bound FSAs still need to be adapted if they are to prove valuable in host markets. Adaptation may entail the modification of existing FSAs to suit location circumstances and/or the development of complementary locationspecific FSAs (such as a local brand or distribution channel). It is then argued that these adaptation costs are significantly larger in host regions than in the home region, as "MNE operations in the host regions function on the basis of an overall FSA bundle that may differ significantly from the one deployed in the home region" (Rugman and Verbeke, 2007, p. 5). This is predicated on an assumption that the host region is significantly more distant (i.e. different) from the home country than are the homeregion countries. In part, the higher adaptation costs in host regions are "a reflection of the 'limited customer value' attributed to home region FSAs" (Rugman and Verbeke, 2004, p. 12). In short, customers (and other stakeholders) in home-region countries are less different from the home country than customers in host region countries. ${ }^{8}$

Home-regional orientation may also be framed through behaviorally-oriented theories. In the behavioral tradition, distance is seen to hinder information flows, the forming of relationships, and the perception of business opportunities. Although behavioral theories are diverse, they are less concerned with cost (and benefit) comparisons as a group and, instead, see risk-averse firms following what might be described as a path of least resistance.

According to the Uppsala model (Johanson and Vahlne, 1977), internationalizing firms initially prefer to target countries with lower "psychic distance" from their home country, ${ }^{9}$ with subsequent investments spanning progressively greater distances. A similar home-region-centric (broadly defined) expansion pattern may also be derived from innovation-adoption-inspired models of internationalization (Andersen, 1993; Cavusgil, 1982). Both of these schools draw heavily on the behavioral theory of the firm (Cyert and March, 1963), espousing that firms intent on containing risks stay in the vicinity of their past practices and the routines that govern them. Such path dependencies are also a key ingredient of cognitive theories, possibly the most behavioral within the behavioral paradigm (Zahra et al., 2005; Buckley et al., 2007; Bingham and Eisenhardt, 2011). From a cognition perspective, home regionalization may also be explained in terms of opportunity recognition: internationalizing firms are 
most likely to discover sales opportunities in near, familiar markets. Home-region orientation may also be the result of deliberate processes to cut complexity and to limit choices to a comprehensible range (Starbuck and Milliken, 1988; Gigerenzer, 2002). The cognitive heuristics adopted by firms may be geographically based, thus constraining them to neighboring countries, or to countries with a shared language (Bingham and Eisenhardt, 2011). ${ }^{10}$

Thus, we can see that a number of theories, economistic or behavioral, are broadly reconcilable with the notion of home regionalization. ${ }^{11}$ In a typical study, one or several of these theories of substance are briefly invoked before the author proceeds to report empirical details of home-regionalization outcomes. Specifications of empirical tests are, however, compromised inasmuch as theories are often highly stylized with regard to home-regionalization behavior. For instance, it rarely articulated how a home-region orientation will unfold over time, or where the end point of firm expansion within (and beyond) the home region will be. The archetypes below begin to shed light on the issue by exploring possible iterations of FSA reach.

Empirical tests of home-regionalization theories are also compromised by research designs that fail to examine the particular mechanism of their favored homeregionalization theory. ${ }^{12}$ For instance, no empirical home-regionalization work to date has made a serious effort to compare adaptation (or transfer) costs between home and host regions. Instead, researchers restrict themselves to observing geographic segment sales. They then infer from such data the (relative) cost-benefits of expanding within the home region or beyond. In actuality, costs are never disentangled from benefits. More importantly, alternative theoretical rationales cannot be ruled out.

These shortcomings are often the result of serious data constraints and the desire for generalizability. While these shortcomings are understandable in an emerging research stream, regionalization scholars need to be circumspect about drawing inferences from these limited empirical tests and more guarded in handing out normative advice. Building more comprehensive theories of home regionalization requires, among other things, an explicit articulation of home-regionalization patterns. The archetypes below detail the universe of possibilities of how home regionalization may actually play out, couched in the language of FSA reach. The articulation of these archetypes has a two-fold purpose: to take a first step towards a tighter theorization of home regionalization and to discuss a more rigorous specification of empirical tests.

\section{Five archetypes}

We identify five archetypes covering the entire spectrum of FSA reach and its evolution. We label them:

(1) Home-country fortress.

(2) Home-region fortress.

(3) Home-region saturation.

(4) Permeable regions.

(5) Flat world.

We must emphasize at the outset that not all of these archetypes are represented in the extant home-regionalization literature. For the purpose of exegesis, our set of five archetypes covers the entire spectrum of possible positions on home 
regionalization (although one could distinguish several variants of a particular archetype, some of which we allude to below).

In outlining each different archetype or pattern, we attempt to uncover the underlying assumptions, such as distinct conceptualizations of the degree and impact of heterogeneity within and across locations. We also explore the implications of such assumptions, both with regard to the dynamics of the expansion process and to the implied boundedness of FSAs. Finally, we consider the likely empirical tests for each archetype and briefly compare it to past research results. In some instances, the evidence stacks up quickly against particular archetypes. In other cases, there is a range of promising empirical avenues that warrants further exploration.

Figure 1 represents our attempt to visualize the bounds of FSA reach under each archetype, with solid lines reflecting impenetrable barriers and dotted lines more permeable bounds. For simplicity's sake, Figure 1 presents a three-region (triad) world.

Figure 1. The bounds of FSA reach under each archetype

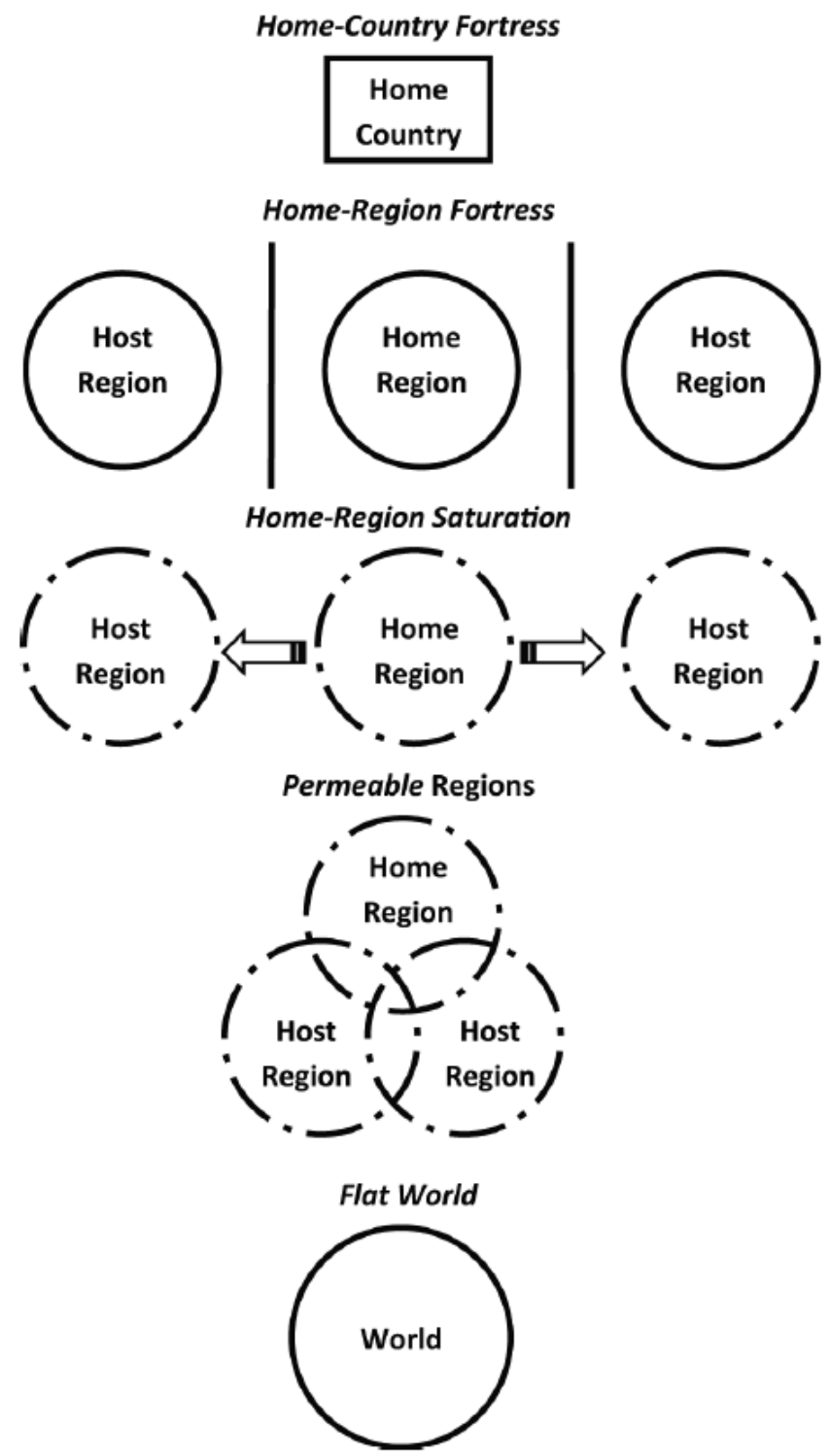


The home-country fortress archetype presents a world where FSAs have no currency in foreign markets, thus rendering all market-seeking international business - within and outside the home region - unviable. The home-region fortress reflects a state of affairs where international leveraging of FSAs is possible, but only within a firm's home region. The home-region saturation archetype invokes a scenario where MNEs deploy their FSAs in home-region markets before exploring opportunities in host-region environments. In a world with permeable regions, the boundaries between the regions are even more porous. Home and host regions are viewed as containing distinct and diverse countries. FSA reach now becomes more selective, with firms expanding into some host regional markets while also pursuing options closer to home. Finally, the flat world scenario sees regional (and national) boundaries as simply irrelevant such that firms face no barriers to international expansion. These five archetypes represent five distinct patterns concerning the extent and dynamics of home-region (and homecountry) orientation. Strictly speaking, the first and last type both repudiate any form of home regionalization and bookend the more interesting permutations in the middle.

\section{Exploring the archetypes}

Home-country fortress archetype

The home-country fortress archetype assumes FSAs to be completely immobile across any national boundaries due to irrelevance or prohibitive adaptation or transfer costs. This condemns firms to eternal domestic status. ${ }^{13}$ The region concept has no role in this archetype as the barriers to cross-border expansion are insurmountable.

This requires national markets to be so different from each other (in terms of customers, competitors, and stakeholders) as to render them irredeemably hostile. Firms are unable to leverage any existing advantage. They cannot conceive of any way to cost-effectively adapt to a potential host nation's (let alone host region's) idiosyncrasies. Alternatively, transfer costs are prohibitive. A hypothetical world of impenetrable language and cultural differences, xenophobia on the part of foreign customers, hostile host governments, an impervious competitive context, and punishing transportation costs would produce such an outcome. Firms being held captive by their domestic mindsets and routines would be a possible behavioral account of such a world.

The empirical evidence against this archetype as a pervasive state of affairs is overwhelming. ${ }^{14}$ Numerous firms cater to customers in international markets and have done so for many decades. Trade of goods and services across international borders currently amounts to almost 30 percent of world GDP. More importantly, 2010 sales by foreign affiliates totalled US\$33 trillion, just over half of world GDP (UNCTAD, 2011, Table 1.5). ${ }^{15}$ At least in part, these statistics reflect firms successfully projecting their FSAs across national borders, whether it be via exports, licensing or FDI.

On the other hand, it should also be noted that the large majority of firms on the planet do not have an international sales presence and, perhaps, find it impossible to deploy their FSAs across national borders. Given IB researchers' preoccupations with MNEs, we must remind ourselves that they are "sui generis": firms that go abroad tend to be the most productive ones among the population (Yeaple, 20o9). Clearly, most firms choose to remain in their home country, and even some of the world's corporate giants have not yet found the need or capacity to extend FSA reach across borders. ${ }^{16}$ 


\section{Home-region fortress archetype}

The home-region fortress archetype grants firms scope to internationalize but only within the bounds of their home region. FSAs are not relevant or cannot profitably be deployed beyond home-region borders. While the same economistic or behavioral arguments as identified with the first archetype apply, this time it is at the home region level. Therefore, no sales (and, by inference, profits) can be achieved outside these bounds. This implicitly assumes an intra-regional environment that is relatively homogenous coupled with host-region countries that are (or are perceived by MNE decision-makers to be) profoundly different.

An example of a view indicative of the home-region fortress archetype would be the suggestion that:

Firms will stay at home because a home-regional presence allows the MNE to gain all the potential economies of scale and scope and/or differentiation advantages within its home triad market. The additional scale, scope or differentiation advantages to be gained by going global are not sufficient to compensate for the enhanced risks (Rugman and Brain, 2003, p. 7).

With this archetype, within-region heterogeneity must also be so low as to make every country within the region more alike (less distant) than any country outside the region. A region's outlier countries could not be closer to countries in another region.

Region-wide efforts to integrate markets - the EU being the most prominent example - may serve to reduce administrative and other distances within the region and the corresponding costs of intra-regional expansion. Over time, such integration may have a homogenizing effect on cultural and socio-economic affairs. Nevertheless, it is still a substantial leap to claim that such processes bar market-seeking in other regions. ${ }^{17}$

The region concept looms large within the home-region fortress archetype. It treats the home region as all there is. The internationalization story ends at the homeregional boundary. ${ }^{18}$ Firms may deploy their FSAs within the region, thus building up economies of scale and scope across multiple countries, but these cost savings do not render host region activity viable. Similarly, any region-specific knowledge concerning adaptation cannot be transferred cost-effectively into host regions. Learning over time within the home region does not bring host regions into reach.

This archetype has a clear, testable outcome. MNE sales should be confined to the home region. Even allowing for some misguided market-seeking in hostile hostregion markets, firms would be expected to beat a quick retreat. Empirically, any evidence of substantive and enduring host region sales would refute this strong version of the home-regionalization thesis. Cross-sectional data on MNE sales would suffice.

Preliminary evidence is, again, damning of this perspective. MNEs do extend their sales reach beyond the home region, at least when defined using the traditional triad of Europe, Asia Pacific and North America. In Rugman and Oh's sample of 655 of the world's largest corporations, home region sales averaged 75.9 percent (Rugman and Oh, 2012, p. 8). In other words, around 24.1 percent of a typical firm's sales occurred outside the home region. Coupled with an average domestic sales portion of 65.6 percent of total sales, home region international sales stood in the vicinity of 10.3 percent, or 42.9 percent of total international sales. ${ }^{19}$ Clearly, home region boundaries are not impenetrable. Similarly, in Rugman's (2005) original classification, only 58 firms out of a total 365 reported exclusively home-regional sales, the majority of which were solely domestic firms. This is strong prima facie evidence that, for a considerable 
portion of firms, home-region borders do not represent a meaningful barrier to expansion. In short, it seems that overall home-region borders are porous.

Of course, even if the data were supportive of this archetype, it could not verify the existence of a home-region fortress. Firms may yet have to explore host-region options, possibly because they are still preoccupied with pursuing opportunities in the home region, which leads us to our next, dynamic archetype.

\section{Home-region saturation archetype}

The home-region saturation archetype eases the assumption of impenetrable regional boundaries. There is still a clear hierarchy, with all the countries of the home region more familiar than countries elsewhere. But, the region no longer constitutes an absolute barrier. Countries in other regions eventually come into reach. As such, a dynamic phenomenon is envisaged: firms will engage in host-regional expansion but only once all opportunities within the home region have been exhausted.

The region concept takes center stage, as with the preceding archetype, and the region is the logical and natural domain for FSA exploitation. Again, (perceived or real) within-region heterogeneity is lower, rendering all countries within the region more alike than any country outside the region. Crucially, however, differences across regions no longer preclude returns to FSAs. The upshot would be a dynamic such that the "MNE first expands within its home region and then goes to other regions" (Rugman et al., 2007, p. 306).

With this archetype, firms' market entry sequences reveal their assessment of the likely cost/benefits (from an economistic perspective) or the easiest choices (from a behavioral perspective). It further assumes that realizing FSA benefits in a regional market is through focused attention and build-up of sufficient scale/scope and market share.

Exactly how market saturation might come about in terms of country-choice ordering has, to our knowledge, never been articulated. There are at least two possible variants: sequential market saturation, or simultaneous market saturation. Firms may sequentially target national markets in the region. That is, they build up market share in each country to the desired level before moving on to the next country within the region. This implies that economies of scale and scope primarily apply at the national level. Alternatively, such economies may chiefly play out at the regional level (e.g. due to limited pressures to adapt products or services to individual countries) and prompt the simultaneous pursuit of multiple (or indeed all) countries via region-wide internationalization.

At an empirical level, the saturation archetype is fraught with difficulty. The threshold that constitutes market saturation is likely to vary from industry to industry and on a firm-by-firm basis. There is also a certain circularity in this position: commencement of host regional sales, at any point, could be erroneously construed as an indication of a saturated home-region market.

Testing this dynamic archetype imposes significant demands on the data used. Cross-sectional data is clearly inadequate. For instance, in the case of a firm that currently has substantial host-region sales, did those sales commence once homeregion sales had leveled off, or was it a messier expansion trajectory? Similarly, with a mere snapshot of firm sales, the researcher cannot know whether firms have reached an endpoint (thus supporting the home-region fortress archetype) or merely a 
transition point. For instance, consider a firm that currently has all its sales confined to the home region. Is that where it will stop, or will it continue expanding? For this very reason, confirmation of the saturation archetype remains challenging even with longitudinal data.

A conceivable repudiation is more straightforward: the continued increase in home-region sales during periods of host-region expansion would clearly contravene the saturation archetype. A weaker test might suggest that, once a critical sales threshold has been achieved at home, firms will switch to host regions but without completely abandoning growth in the home region. But how do we determine an acceptable switching point for deeming the region saturated? Very soon this becomes a game of arbitrary thresholds and transitional overlaps, rendering this archetype both difficult to falsify and verify with conventional data. In the end, it may only be possible to assess the saturation view by exploring managers' decision-drivers.

Keeping these caveats in mind, the prima facie evidence does not seem overly supportive of saturation-style behavior. As noted earlier, Osegowitsch and Sammartino (2007) reported that 2001 international sales within home regions averaged 10.6 percent of firm sales, while the inter-regional share stood at 23.8 percent. When compared to figures for the same firms in 1991, inter-regional sales had grown somewhat faster than home-region international sales (at 15.1 and 12.9 percent, respectively). For the period 2000 to 2007, Rugman and Oh (2012) reported a drop in the average home-regional sales share from 77.3 to 74.5 percent. In conjunction with a more marked decrease in domestic sales, this suggests that international sales within and beyond the region grew at comparable rates. Overall, there is little evidence to suggest saturation-style behavior as large firms, on average, expanded home- and hostregion sales simultaneously. We caution, however, that simple averages may mask considerable diversity in firm trajectories (see also the discussion of central tendency in the discussion and conclusion section).

\section{Permeable-region archetype}

The preceding two archetypes regarded the home region as a homogenous entity to the point that each member country is more similar to the home country than all countries outside the home region. The permeable-region archetype relaxes this assumption and allows for greater country diversity within regions (Banalieva and Dhanaraj, 2012). While, overall, there is still less heterogeneity within regions than across them, a variegated picture emerges. The region boundary becomes even more porous. As a result, country identity begins to matter and the region concept recedes into the background.

On balance, the firm is still more likely to choose a home-region country as its next sales destination. However, comparing the similarity of potential host countries vis-à-vis the firm's home country will trigger a rank-ordering that sees some hostregion locations promoted ahead of some home-region options. In short, country similarities no longer neatly follow regional boundaries; intra-regional diversity is being recognized. This archetype concedes the possibility that economies of scale and scope extend across regional boundaries, and that learning about and from internationalization may have little region-specificity. Similarly, there are no powerful region-wide routines or heuristics driving a strong preference for the home region. 
The permeable region perspective is a broad church. Most authors active in the home-regionalization debate would seem to subscribe to a more or less stringent form of the permeable-region archetype. Their particular variant is evident from their operationalization of particular home- or host-regional thresholds. For example, Rugman's (2005) original investigation used a simple $\geq 50$ percent home region sales cut-off to identify home-region MNEs. Osegowitsch and Sammartino (2008), conscious of the sensitivity of the data to the imposition of a particular categorization scheme, employed several different thresholds, as did Delios and Beamish (2005). Regionalization thresholds can also be further tweaked by normalizing the data. For instance, a number of papers neutralize substantial home-country effects by comparing host regions with home region net of home-country sales (Banalieva and Santoro, 2009). Others go even further and normalize sales figures by accounting for regional differences in GDP (Asmussen, 2009). ${ }^{20}$

These different research designs constitute more or less stringent tests of the permeable-region archetype. It remains unclear, however, what level of porousness would ultimately refute or confirm the overarching archetype. Once again, this becomes a question of thresholds.

Confirmation of the permeable-region thesis in its least stringent operationalization - simply pitting firms' market share in the home region against their market shares in host regions - is, in one sense, banal. Consider the next logical, lower level. For the overwhelming majority of firms, home-country market share is disproportionately large when compared to shares in other countries of the home region. As a result, one might conclude that FSAs are in fact nation-bound. To paraphrase Rugman (2001), home-regional strategy is a myth. This is not to disparage a regional perspective but, rather, to illustrate that the game of thresholds is ultimately futile. The fact that firm sales in particular locales tend to be disproportionately large simply reflect firms' origins - in particular localities, countries, and regions. To take this to an even lower level, a British firm hailing from the county of Essex is highly likely to hold a disproportionate market share in Essex compared to other British counties. By itself, this is insufficient evidence to conclude that the county level is the most appropriate level of analysis and that firms should abandon ambitions to build a national presence.

\section{Flat-world archetype}

This leads us to the final, flat world archetype. Here, region (as well as country) boundaries are irrelevant as firms experience no barriers to international expansion and FSAs are consistently transferable. This is in agreement with a Levittian world where there is no need to adapt due to considerable market homogeneity (within and across all regions) (Levitt, 1983). Alternatively, a flat world would be one where firms have an effortless ability to adapt FSAs to any set of circumstances, or where the benefits of worldwide integration completely overwhelm any pressures for responsiveness. Such circumstances may be brought about by the sort of flattening trends heralded by Friedman (2005) and others, including advances in communication and information technology, political changes, and convergence in societal expectations and firm behaviors. In a behavioral sense, a flat world would be one 
unconstrained by choice-narrowing routines or heuristics, and characterized by global mindsets and effortless and transferable learning.

Empirical support for this final archetype is scarce. The key piece of contrarian evidence is the firms' strong propensity to derive disproportionate sales revenue from their domestic markets, as stated earlier. Yet, in a flat world, national boundaries should not matter. Similarly, Rugman and Verbeke (2004) detect an insignificant share of "global firms" and Asmussen (2009) finds little evidence for a "globalized perspective" on firm expansion (and, by inference, FSA reach). On balance, we conclude that there is scant support for a flat world archetype in past investigations.

\section{Discussion and conclusion}

This paper contributes to the emerging body of home-regionalization research by charting the full range of possibilities of how firms may interact with their home region. Each of our five archetypes can be viewed as a possible state of the world in which a qualitatively different level of home-region (or -country) orientation prevails. In explaining each, we have sketched likely explanations in tune with existing economistic and behavioral theories. Our archetypes also serve to highlight and address particular empirical challenges in home-regionalization studies.

Empirical studies in the home-regionalization area are mostly concerned with central tendency (i.e. what the typical MNE does) and rarely distinguish the prevalence of particular archetypes (see Aggarwal et al., 2011, for an exception). These works consistently find most firms to be more active in their home region than in host regions. In short, there is a home-region orientation. But the same evidence also rejects the notion of the home-region boundary as a genuine barrier to expansion: many MNEs do cross the home-regional boundary, to varying degrees. ${ }^{21}$ Thus, the home region (or rather sales in the home region) now merely serves as a benchmark for the diagnosis of home region orientation.

While there is a lively debate about the extent of, and change in, home-region orientation and its practical and theoretical significance, the focus on overall outcomes (i.e. an overall geographic sales orientation) may have distracted us from the underlying phenomenon theorized in transaction cost accounts of home regionalization. The five archetypes set out herein refocus discussion on the regional boundedness of FSAs. More importantly, they also raise deeper questions about what exactly constitutes the region and its effect on firm expansion.

The concept of distance is central to IB theorizing. IB researchers have long been comfortable stating that proximate locales and more familiar markets are more easily penetrated (Vernon, 1971; Johanson and Vahlne, 1977; Davidson, 1983). The region may then simply be a parsimonious way of saying country-to-country distance matters: inasmuch as the region contains proximate countries, firm expansion choices are region-based. Yet for the region to be a meaningful concept above and beyond simply capturing distance, it would need to do more. Here we echo the comments by Aguilera, Flores and Vaaler that future studies need to "tease out regional from country level effects" (Aguilera et al., 2007, p. 17). The authors' argument is concerned with statistically disentangling country (distance) explanations from region explanations. Our own discussion of the region effect is strictly conceptual, focused on the phenomenon of FSA reach. 
To establish the region concept as something more than a proxy for conventional country-distance explanations, we would need to confirm the region as the natural domain for strategic decision making. A genuine region effect would entail the regionwide creation, leveraging, and adaptation of FSAs.

Extant empirical work tends to view the identification of a home-region orientation - however operationalized - as sufficient justification for the region concept. In view of our archetypes, we are more guarded. The region matters and is the preeminent geographic arena when it comes to the home-region fortress and saturation archetypes, since they imply a clear hierarchy between home regions and host regions. Under the home-region fortress scenario, a particular bundle of FSAs will reach across the entire home region and no further. In a saturation world, it will reach across the entire home region before extending to host regions (in adapted form). The merit of the region concept is more debatable when it comes to the permeable-region archetype with its less clear cut expansion choices (and even more so with the more fanciful flat world and home-country fortress archetypes).

To further scrutinize the region concept, we need to take a closer look at the archetypes. With the home-region fortress archetype, a genuine region effect would require that the MNE is able to leverage a particular set of FSAs across the entire region, and not leverage them beyond. It would entail the firm tapping benefits and opportunities beyond simply those of an MNE targeting a few neighboring countries. It would require the firm to exploit region-wide FSAs, thus realizing considerable gains from regional economies of scale, scope and learning.

If we observe expansion beyond the home region - whether as the next phase of a saturation archetype or as a permeable-regions archetype - we face a similar set of questions. Is the observed behavior a matter of FSA bundles being adapted in a regionspecific way? Or, are new region-specific sets of FSAs being built? Either observation would confirm a genuine region effect beyond simpler country-distance explanations. The permeable-region archetype in particular casts some doubt on a genuine region effect: the simultaneous pursuit of home-region and host-region expansion suggests inter-regional FSAs that are being adapted to each national market, both of which defy a region-level explanation. ${ }^{22}$

At this stage, we do not have convincing answers to any of the issues raised above. The regionalization literature engages in a rather stylized discussion of firm behavior and advantage (as does this paper) to draw conclusions about the merit of the region. To definitively establish the region concept as something more than a convenient shortcut for conventional country-distance explanations, we would need to be confident that the region does loom large in the building and leveraging of FSAs.

To bolster the case for the region concept, future empirical efforts need to study the specifics of regionalization behavior. For instance, the use of firm-level countrybased data (necessitating the use of more fine-grained datasets) would allow us to discount the possibility of sales from a couple of neighboring countries driving regional sales. In one rare example of such an approach, Aggarwal et al. (2009), found that:

The vast majority of firms do not fully penetrate their home region. Very few firms are active in more than one-third of countries in their region, and our findings are consistent with a pattern of internationalization whereby firms expand beyond their home region long before they have exhausted more geographically close markets (Aggarwal et al., 2009, p. 1). 
But the most definitive way of establishing just how large the region looms in firms' strategizing lies in detailed studies of firms' FSA bundles across locations. Studies of firms' decision-making processes, and in particular their conception of the region, are another promising avenue to consolidate the region. Beyond that, there is the question of what actually drives the recognition of the region in the creation, adaptation, and leveraging of FSAs, which would get us closer to the underlying theories of substance. Is it the sort of calculus posited by economistic theories or is its recognition founded on more behavioral processes? For instance, do firms gradually get locked into region-centric mindsets as their initial location decisions unfold (i.e. is it a path dependent phenomenon)? Or do firms simply act on external cues such as the legitimacy and recognition of a particular region?

Future research opportunities are also linked more directly to the archetypes created herein. Anecdotal evidence would suggest that, in any population of large firms, several or possibly all of our archetypes have real life exemplars (although the bookend archetypes would be much rarer). The fact that a significant portion of firms are able to expand into host regions, while others are confined to their home region or even home country, is informative in itself. It reminds us that firm behavior is highly varied, an amalgam of external and internal circumstances, including industry forces and broader institutional pressures (at the home-country or home-region level) as well as the extent and nature of the firm's FSAs and its administrative heritage. The articulation of different archetypes, such as the ones in this paper, may serve as a stimulus for building a more contingent theory of firm internationalization incorporating a regional level. It constitutes a first step towards a discovery of the relevant internal and external contingencies driving particular regionalization patterns.

\footnotetext{
${ }^{1}$ We follow Banalieva and Dhanaraj's (2013) example and opt for the less pejorative home region "orientation" rather than "bias".

${ }^{2}$ Firm assets are more ambiguous in this regard. It is impossible to unequivocally assign assets to a particular motive. Foreign assets may be dedicated to furthering sales (e.g. in the form of a local sales branch or service centre) or may be aimed at capturing local resources of various kinds (e.g. in the form of a development center or production facility).

${ }^{3}$ There is also debate as to whether geography should play the singular/prime role in defining regions, rather than cultural, administrative, political, linguistic, economic, or other factors (Aguilera et al., 2007). Moreover, there is debate as to whether researchers should define the regions ex ante or ex post (Vaaler et al., 2007).

${ }^{4}$ For instance, Ghemawat (2001) argues that distance between two countries can manifest along four basic dimensions: cultural, administrative, geographic and economic. For a more comprehensive treatment of distance in the literature, we refer the reader to Dow and Larimo (2009). For a very recent, novel conceptualization of distance we suggest Boeh and Beamish (2012).

5 We note that Ghemawat (2001) is careful to emphasize that distance may also be advantageous, depending on the characteristics of the industry and company strategy.

${ }^{6}$ Distance is also seen as problematic by increasing the need for adaptation (Leonidou and Katsikeas, 1996) and giving rise to uncertainty, thus curbing hierarchical entry modes (Zhao et al., 2004).
} 
7 The term liability of foreignness (LOF) is an unfortunate choice in this context. LOF is an established construct in the IB literature (Zaheer, 1995), comparing the performance of subsidiaries of foreign-based MNEs with that of local businesses. By contrast, the relevant benchmark used in home regionalization studies is a given firm's sales performance in the home region relative to its sales performance in host regions.

${ }^{8}$ While extant theory emphasizes the customer-facing side (and the corresponding adaptation costs across regions), explanations cast in terms of internal transfer costs are equally plausible. For instance, absorptive capacity (Cohen and Levinthal, 1990) is a crucial concept in the explanation of knowledge flows. To be able to source and use pieces of knowledge, the receiving unit requires absorptive capacity, i.e. the ability "to recognize the value of new information, assimilate it, and apply it to commercial ends" (Cohen and Levinthal, 1990, p. 128). While Cohen and Levinthal's conception is focused on the external sourcing of knowledge, this perspective might also be applied to the MNE, and its subsidiaries' attempts to absorb parent FSAs. Inasmuch as absorptive capacity is impacted by various forms of distance, transfers to host regional subsidiaries may prove more costly, even prohibitively so. Empirical evidence for the deleterious effect of distance on knowledge transfer effectiveness can be found in Ambos and Ambos (2009).

${ }^{9}$ Psychic distance is defined as those factors preventing or disturbing the flow of information between the firm and the target country, including linguistic, institutional, cultural, and political factors. Notwithstanding exceptional cases such as the pairing of the UK and Australia, psychic distance is positively correlated with geographic distance.

${ }^{10}$ In their study of the selection heuristics of six MNEs, Bingham and Eisenhardt (2011) found one to have a strong "English-speaking markets heuristic" that assisted them in narrowing their choice set.

${ }^{11}$ For greater detail on these (and additional) theories convergent with home regionalization outcomes, we refer the reader to a wide-ranging review by Wolf et al. (2012).

${ }^{12}$ This situation is not uncommon in IB, with researchers frequently testing for hypothesized outcomes rather than the actual, underlying mechanism.

${ }^{13}$ International engagement fueled by motives other than market-seeking, such as strategic asset-seeking, may still be feasible.

${ }^{14}$ The archetype may be common in some specific industries and home countries, however. Vahlne and Nordstrom (1993), for instance, suggest that competition in industries such as fish breeding is overwhelmingly national. Rugman and Li (2007) report exceedingly high levels of domestic sales for China's largest firms.

${ }^{15}$ Naturally the share of foreign affiliates in terms of value added is significantly less, estimated at just over 10 percent of world GDP (UNCTAD, 2011, Table 1.5).

${ }^{16}$ Ghemawat (2011) reports that, in 2004, less than one percent of all US companies had foreign operations, and of those, the largest fraction operated in just one foreign country. The median operated in two foreign countries, and 95 percent in fewer than two dozen countries. Even among the world's largest firms (Fortune's Global 500), a sizeable number have no international sales presence. Rugman (2005) has sales data for 365 of these firms. A total of 36 of these firms had no international sales in 2001, representing almost 10 percent of the sample. It is highly probable that an even higher proportion of the

non-available firms are solely domestic given they are headquartered in emerging economies and/or are local monopolists. In a follow-up study, Rugman and Oh (2007) report that domestic sales for their expanded sample of 386 Fortune Global 500 firms constitute, on average, 65 percent of total sales. In other words, even established MNEs have a strong domestic sales focus.

${ }^{17}$ There appears to be a parallel assumption that intra-regional integration simultaneously alienates the home region from other regions. However, it is far from clear whether rising intra-regional trade ratios or occasional trade disputes between the big trading blocs (Rugman, 
2000, 2005) are sufficient evidence to support such a narrative. It is indisputable that negotiations concerning worldwide trade and investment liberalization under the WTO have been floundering for many years while agreements on a bilateral and multi-country basis have proliferated. While many of these agreements have led to further regional integration, many of them extend across (continental) regional boundaries. In other words, intra-regional integration would seem to go hand in hand with integration across regions. The Trans-Pacific Partnership (TPP) is a case in point. The original agreement was signed by Brunei, Chile, New Zealand, and Singapore in 2005. Many other countries, including Australia, Malaysia, Peru, Japan, US, Vietnam, Canada, and Mexico have since commenced negotiations to join the group. Countries may also be actively looking for partners outside their region for geopolitical reasons. For instance, it is often maintained that many of the bilateral (and multilateral) deals South East Asian nations conduct with countries outside Asia, chiefly the US, are designed to escape China's geopolitical bear hug (Murphy and

Mitchell, 2012). In turn, some commentators suggest that strong US engagement in Asia in the form of political and economic links is part of its ambition to contain its emerging rival China. Such geopolitical power plays regularly across regional boundaries.

${ }^{18}$ Strictly speaking, there is no guarantee that firms complying with this archetype will expand throughout the entire home region. Returns on FSAs may actually become negative beyond a small number of countries, i.e. beyond a particular sub-region. However, as set out in the discussion and conclusion section, if reach is confined to a few proximate countries within the region, it is debatable whether a regional lens is superior to more conventional explanations based on country distance.

${ }^{19}$ For a sub-sample of the original Rugman (2005) dataset, using only firms continually represented in the rankings from 1991 to 2001, Osegowitsch and Sammartino (2007) report an almost identical rest-of-home-region sales figure of 10.6 percent.

${ }^{20}$ Another distinction can be drawn between contributions comparing the home region with the rest of the world (ROW) (Asmussen, 2009; Goerzen and Asmussen, 2007), and others comparing it with individual host regions (Rugman, 2005; Osegowitsch and Sammartino, 2007, 2008). The former do not distinguish individual regions and, thus, are incapable of recognizing the phenomenon of bi-regionalism (Rugman and Verbeke, 2004; van Tulder et al., 2001).

${ }^{21}$ In Rugman's (2005) classification, only 58 firms out of a total 365 reported exclusively home region sales, the majority of which were solely domestic firms.

${ }^{22}$ The permeable regions archetype does contain several variants. Expansion beyond the home region may play out as expansion in one host region or as expansion across both host regions (plus the remaining non-triad world). The first variant is clearly more suggestive of a region effect than is a more dispersed expansion. We note that various early regionalization works find significant numbers of bi-regional firms (Rugman, 2005; Osegowitsch and Sammartino, 2007), i.e. those with a significant presence in the home region and one other host region.

\section{References}

Aggarwal, R., Berrill, J., Hutson, E. and Kearney, C. (2009), "Are the world's largest firms regional or global?", paper presented at the 2009 Academy of International Business Conference, San Diego, CA, June 27-30.

Aggarwal, R., Berrill, J., Hutson, E. and Kearney, C. (2011), "What is a multinational corporation? Classifying the degree of firm-level multinationality", International Business Review, Vol. 20 No. 5, pp. 557-77. 
Aguilera, R.V., Flores, R.G. and Vaaler, P.M. (2007), "Is it all a matter of grouping? Examining the regional effect in global strategy research", in Tallman, S. (Ed.), International Strategic Management: A New Generation, Edward Elgar Publishers, Northampton, MA.

Ambos, T. and Ambos, B. (2009), "The impact of distance on knowledge transfer effectiveness in multinational corporations", Journal of International Management, Vol. 15 No. 1, pp. 114.

Andersen, O. (1993), "On the internationalization process of firms: a critical analysis", Journal of International Business Studies, Vol. 24 No. 2, pp. 209-31.

Arregle, J., Beamish, P. and Hérbert, L. (2009), “The regional dimension of MNEs' foreign subsidiary localization”, Journal of International Business Studies, Vol. 40 No. 1, pp. 86107.

Asmussen, C.G. (2009), "Local, regional, or global? Quantifying MNE geographic scope", Journal of International Business Studies, Vol. 40 No. 7, pp. 1192-205.

Banalieva, E.R and Dhanaraj, C. (2013) "Home-region orientation in international expansion strategies”, Journal of International Business Studies, Vol. 44 No.2, pp.89-116.

Banalieva, E.R. and Santoro, M.D. (2009), "Local, regional, or global? Geographic orientation and relative financial performance of emerging market multinational enterprises", European Management Journal, Vol. 27 No. 5, pp. 344-55.

Bartlett, C.A. and Ghoshal, S. (1989), Managing Across Borders: The Transnational Solution, Harvard Business School Press, Boston, MA.

Bingham, C.B. and Eisenhardt, K.M. (2011), "Rational heuristics: the 'simple rules' that strategists learn from process experience”, Strategic Management Journal, Vol. 32 No. 13, pp. 1437-64.

Boeh, K.K. and Beamish, P.W. (2012), "Travel time and the liability of distance in foreign direct investment: location choice and entry mode”, Journal of International Business Studies, Vol. 43 No. 5, pp. 525-35.

Buckley, P.J. and Ghauri, P.N. (2004), "Globalization, economic geography and the strategy of multinational enterprises”, Journal of International Business Studies, Vol. 35 No. 2, pp. 8198.

Buckley, P.J., Devinney, T.M. and Louviere, J.J. (2007), "Do managers behave the way theory suggests? A choice-theoretic examination of foreign direct investment location decisionmaking", Journal of International Business Studies, Vol. 38 No. 7, pp. 1069-94.

Cavusgil, S.T. (1982), "Some observations on the relevance of critical variables for internationalization stages", in Czinkota, M.R. and Tesu, G. (Eds), Export Management: An International Context, Praeger, New York, NY, pp. 276-86.

Cheng, J.L.C. (2007), "Critical issues in international management research: an agenda for future advancement”, European Journal of International Management, Vol. 1 Nos 1/2, pp. 23-38.

Cohen, W.M. and Levinthal, D.A. (1990), "Absorptive capacity: a new perspective on learning and innovation", Administrative Science Quarterly, Vol. 35 No. 1, pp. 128-52.

Cyert, R.M. and March, J.G. (1963), A Behavioral Theory of the Firm, Prentice Hall, Englewood

Cliffs, NJ. Davidson, W.H. (1983), "Market similarity and market selection: implications for international marketing strategy", Journal of Business Research, Vol. 11 No. 4, pp. 439-56.

Delios, A. and Beamish, P.W. (2005), "Regional and global strategies of Japanese firms", Management International Review, Vol. 45 No. 1, pp. 19-36.

Dow, D. and Larimo, J. (2009), "Challenging the conceptualization and measurement of distance and international experience in entry mode choice research", Journal of International Marketing, Vol. 17 No. 2, pp. 74-98.

Doz, Y., Santos, J. and Williamson, P. (2001), From Global to Metanational: How Companies Win in the Knowledge Economy, Harvard Business School Press, Boston, MA.

Dunning, J.H. (2000), "The eclectic paradigm as an envelope for economic and business theories of MNE activity", International Business Review, Vol. 9 No. 2, pp. 163-9o. 
Enright, M.J. (2005), "Regional management centers in the Asia-Pacific", Management International Review, Vol. 45 No. 1, pp. 59-82.

Ethier, W.J. (1998), “The new regionalism”, Economic Journal, Vol. 108 No. 449, pp. 1149-61.

Filippaios, F. and Rama, R. (2008), "Globalization or regionalization? The strategies of the world's largest food and beverage MNEs”, European Management Journal, Vol. 26 No. 1, pp. 59-72.

Flores, R.G. and Aguilera, R.V. (2007), "Globalization and location choice: an analysis of US multinational firms in 1980 and 2000", Journal of International Business Studies, Vol. 38 No. 7, pp. 1187-210.

Friedman, T. (2005), The World is Flat, Penguin, New York, NY.

Ghemawat, P. (2001), "Distance still matters: the hard reality of global expansion", Harvard Business Review, Vol. 79 No. 8, pp. 137-47.

Ghemawat, P. (2003), "Semiglobalization and international business strategy", Journal of International Business Studies, Vol. 34 No. 2, pp. 138-52.

Ghemawat, P. (2005), "Regional strategies for global leadership", Harvard Business Review, Vol. 83 No. 12, pp. 98-107.

Ghemawat, P. (2007), "Managing differences: the central challenge of global strategy", Harvard Business Review, Vol. 85 No. 3, pp. 56-68.

Ghemawat, P. (2011), “The cosmopolitan corporation”, Harvard Business Review, Vol. 89 No. 5, pp. 92-9.

Gigerenzer, G. (2002), "The adaptive toolbox", in Gigerenzer, G. and Selten, R. (Eds), Bounded Rationality: The Adaptive Toolbox, Massachusetts Institute of Technology, Boston, MA, pp. 37-50.

Goerzen, A. and Asmussen, C.G. (2007), "The geographic orientation of multinational enterprises and its implications for performance", in Rugman, A.M. (Ed.), Research in Global Strategic Management: Vol. 13. Regional Aspects of Multinationality and Performance, Elsevier, Amsterdam, pp. 65-83.

Hennart, J.M.A. (2007), "The theoretical rationale for a multinationality - performance relationship", Management International Review, Vol. 47 No. 3, pp. 423-52.

Johanson, J. and Vahlne, J.E. (1977), "The internationalisation process of the firm - a model of knowledge development and increasing foreign market commitments", Journal of International Business Studies, Vol. 8 No. 1, pp. 23-32.

Leonidou, L.C. and Katsikeas, C.S. (1996), "The export development process: an integrative review of empirical models", Journal of International Business Studies, Vol. 27 No. 3, pp. 517-51.

Levitt, T. (1983), “The globalization of markets”, Harvard Business Review, May/June, pp. 92102.

Luo, Y. and Rui, H. (2009), "An ambidexterity perspective toward multinational enterprises from emerging economies”, Academy of Management Perspectives, Vol. 23 No. 4, pp. 4970.

Morrison, A.J., Ricks, D.A. and Roth, K. (1991), "Globalization versus regionalization: which way for the multinational?", Organizational Dynamics, Vol. 19 No. 3, pp. 17-29.

Murphy, J. and Mitchell, A. (2012), "Pacific trade deal risks new China rift", Australian Financial Review, p. 8, July 16.

Osegowitsch, T. and Sammartino, A. (2007), "Exploring trends in regionalization", in Rugman, A.M. (Ed.), Research in Global Strategic Management: Vol. 13. Regional Aspects of Multinationality and Performance, Elsevier, Amsterdam, pp. 45-64.

Osegowitsch, T. and Sammartino, A. (2008), "Reassessing (home-)regionalization", Journal of International Business Studies, Vol. 39 No. 2, pp. 184-96.

Piekkari, R., Nell, P.C. and Ghauri, P.N. (2010), "Regional management as a system", Management International Review, Vol. 50 No. 4, pp. 513-32.

Rugman, A.M. (2000), The End of Globalization, Random House, London. 
Rugman, A.M. (2001), "Viewpoint: the myth of global strategy", International Marketing Review, Vol. 18 No. 6, pp. 583-8.

Rugman, A.M. (2005), The Regional Multinationals: MNEs and "Global" Strategic Management, Cambridge University Press, Cambridge.

Rugman, A.M. and Brain, C. (2003), "Multinational enterprises are regional, not global", Multinational Business Review, Vol. 11 No. 1, pp. 3-12.

Rugman, A.M. and Li, J. (2007), "Will China's multinationals succeed globally or regionally?", European Management Journal, Vol. 25 No. 4, pp. 333-43.

Rugman, A.M. and Oh, C.H. (2007), "Multinationality and regional performance, 2001-2005", in Rugman, A.M. (Ed.), Research in Global Strategic Management: Vol. 13. Regional Aspects of Multinationality and Performance, Elsevier, Amsterdam, pp. 31-43.

Rugman, A.M. and Oh, C.H. (2010), "Does the regional nature of multinationals affect the multinationality and performance relationship?", International Business Review, Vol. 19 No. 5, pp. 479-88.

Rugman, A.M. and Oh, C.H. (2012), "Why the home region matters: location and regional multinationals", British Journal of Management, online "Early View" version.

Rugman, A.M. and Verbeke, A. (2004), "A perspective on regional and global strategies of multinational enterprises", Journal of International Business Studies, Vol. 35 No. 1, pp. 318.

Rugman, A.M. and Verbeke, A. (2005), "Towards a theory of regional multinationals: a transaction cost economics approach", Management International Review, Vol. 45 No. 1, pp. 5-17.

Rugman, A.M. and Verbeke, A. (2007), "Liabilities of regional foreignness and the use of firmlevel versus country-level data: a response to Dunning et al. (2007)", Journal of International Business Studies, Vol. 38 No. 1, pp. 200-5.

Rugman, A.M., Kudina, A. and Yip, G.S. (2007), "The regional dimensions of UK multinationals", in Rugman, A.M. (Ed.), Research in Global Strategic Management: Vol. 13. Regional Aspects of Multinationality and Performance, Elsevier, Amsterdam, pp. 297315.

Simon, H.A. (1979), Models of Thought Volume 1, Yale University Press, New Haven, CT.

Starbuck, W.H. and Milliken, F.J. (1988), "Challenger: fine-tuning the odds until something breaks", Journal of Management Studies, Vol. 25 No. 4, pp. 319-40.

UNCTAD (2011), World Investment Report 2011, United Nations, Geneva.

Vaaler, P.M., Aguilera, R.V. and Flores, R.G. (2007), "New methods for ex post evaluation of regional grouping schemes in international business research: a simulated annealing approach", in Ketchen, D.J. and Bergh, D.D. (Eds), Research Methodology in Strategy and Management, Vol. 4, Elsevier, Amsterdam, pp. 161-90.

Vahlne, J.E. and Nordstrom, K.A. (1993), "The internationalization process: impact of competition and experience", International Trade Journal, Vol. 7 No. 5, pp. 529-48.

van Tulder, R., van den Berghe, D. and Muller, A. (2001), Erasmus (S)coreboard of Core Companies: The World's Largest Firms and Internationalization, Rotterdam School of Management, Erasmus University, Rotterdam.

Vernon, R. (1971), Sovereignty at Bay: The Multinational Spread of U.S. Enterprise, Basic Books, New York, NY.

Vernon, R. (1979), "The product cycle hypothesis in a new international environment", Oxford Bulletin of Economics and Statistics, Vol. 41 No. 4, pp. 255-67.

Wolf, J., Dunemann, T. and Egelhoff, W.G. (2012), "Why MNCs tend to concentrate their activities in their home region", Multinational Business Review, Vol. 20 No. 1, pp. 67-91.

Yeaple, S. (2009), "Firm heterogeneity and the structure of US multinational activity", Journal of International Economics, Vol. 78 No. 2, pp. 206-15.

Zaheer, S. (1995), "Overcoming the liability of foreignness", Academy of Management Journal, Vol. 38 No. 2, pp. 341-63. 
Zahra, S.A., Korri, J.S. and Yu, J. (2005), "Cognition and international entrepreneurship: implications for research on international opportunity recognition and exploitation", International Business Review, Vol. 14 No. 2, pp. 129-46.

Zhao, H., Luo, Y. and Suh, T. (2004), "Transaction cost determinants and ownership-based entry mode choice: a meta-analytical review", Journal of International Business Studies, Vol. 35 No. 6, pp. 524-44.

\section{Contact us:}

André Sammartino samma@unimelb.edu.au

Thomas Osegowitsch ot@unimelb.edu.au 